\title{
1 A meta-analysis of global avian survival across species and latitude
}

$$
\text { Micah N. Scholer }{ }^{1} \text {, Matt Strimas-Mackey }{ }^{2} \text {, Jill E. Jankowski }{ }^{1}
$$

3

$4{ }^{1}$ Biodiversity Research Centre and Department of Zoology, University of British Columbia,

5 Vancouver, Canada

$6 \quad{ }^{2}$ Department of Conservation Science, Cornell Lab of Ornithology, Ithaca, NY

7 *Corresponding author information: micahscholer@gmail.com, +64 (027) 257-0301.

8 Department of Zoology, 4200-6270 University Blvd., Vancouver, BC Canada, V6T 1 Z4.

9

10

11

12

13

14

15

16

17

18

19

20

21

22 


\section{Abstract}

25 Tropical birds are purported to be longer lived than temperate species of similar size, but it has

26 not been shown whether avian survival rates covary with a latitudinal gradient worldwide. Here,

27 we perform a global-scale meta-analysis to investigate the extent of the latitudinal survival

28 gradient. We modeled survival as a function of latitude for the separate northern and southern

29 hemispheres, and considered phylogenetic relationships and extrinsic (climate) and intrinsic (life

30 history) predictors hypothesized to moderate these effects. Using a database of 1,004 estimates

31 from 246 studies of avian survival, we demonstrate that in general a latitudinal survival gradient

32 exists in the northern hemisphere, is dampened or absent for southern hemisphere species, and

33 that survival rates of passerine birds largely account for these trends. We found no indication that

34 the extrinsic climate factors were better predictors of survival than latitude alone, but including

35 species' intrinsic traits improved model predictions. Notably, species with smaller clutch size

36 and larger body mass showed higher survival. Our results illustrate that while some tropical birds

37 may be longer lived than their temperate counterparts, the shape of the latitude-survival gradient

38 differs by geographic region and is strongly influenced by species' intrinsic traits. 


\section{INTRODUCTION}

48 Aves, a class represented by around 10,000 species, display a broad diversity of morphologies

49 and behaviors, and also show considerable variation in their lifespan and annual survival. For

50 example, in large-bodied landbirds, such as some raptors and parrots, annual survival is often

51 high (Newton et al. 2016; Maestri et al. 2017) and individuals are long lived, but for small-

52 bodied species like warblers and kinglets, rates of annual survival can be low (DeSante et al.

53 2015; Johnston et al. 2016). While differences in body mass account for some of this variation

54 - larger species tend to live longer than smaller ones (Lindstedt \& Calder 1976, 1981;

55 Promislow 1993; Speakman 2005) - many species live longer or shorter lives than predicted

56 given their body mass (Healy et al. 2014). Other aspects of a species' life history, particularly

57 the demographic cost of reproduction, may explain this residual variation in survival rates

58 (Williams 1966; Stearns 1992; Roff 2002). This view stems from the hypothesis that limited

59 resources (i.e., time and/or energy) result in an allocation trade-off between two competing vital

60 functions; specifically, current reproduction reduces future reproduction and survival. The

61 pivotal survival-reproduction trade-off has been well documented in birds (Ricklefs 1977, 2000;

62 Saether 1988; Linden \& Møller 1989; Martin 1995; Ghalambor \& Martin 2001), and with the

63 observations of early investigators that the number of eggs laid declines from the poles towards

64 the equator (Moreau 1944; Lack 1947; Skutch. 1949), it has given rise to the expectation that

65 tropical species should offset a reduced clutch size by having higher adult survival (Murray

66 1985).

67 There are many studies that suggest high adult survival in tropical birds, the majority of

68 which focus on comparisons between north-temperate systems and the tropics. Early reports of

69 high survival came from studies equating survival estimates with return rates (Snow 1962; 
70 Fogden 1972; Fry 1980; Bell 1982; Dowsett 1985). While these studies deepened our

71 understanding of life-history strategies in tropical birds, survival-rate estimates based on return

72 rates are problematic because they confound estimation of complicated functions of survival rate

73 and capture probability (Nichols \& Pollock 1983; Krementz et al. 1989; Sandercock 2006). More

74 recently, studies employing improved methods for estimating survival via Jolly-Seber (JS) and

75 Cormack-Jolly-Seber (CJS) models, which separate apparent survival (i.e., $\Phi$ : the product of true

76 survival and site fidelity) from encounter probability (Sandercock 2006), have reinforced the

77 idea of higher adult survival at lower latitudes (Faaborg \& Arendt 1995; Johnston et al. 1997;

78 Francis et al. 1999; Peach et al. 2001; McGregor et al. 2007). The generality of these findings,

79 however, has been questioned based on comparisons showing negligible differences in survival

80 between Central and North American birds (Karr et al. 1990), and lower than expected survival

81 rates for birds from South America (Blake \& Loiselle 2008). Other studies have even found

82 higher survival rates for south temperate birds compared to tropical species in Africa (Lloyd et

83 al. 2014). Only one quantitative review has formally addressed latitudinal patterns in adult

84 survival rates of birds using survival estimates derived across a broad range of latitudes. Munoz

85 et al. (2018) showed that adult survival was higher for species in the tropics compared to those in

86 five sites across the north temperate zone, supporting the hypothesis of a latitudinal gradient in

87 survival, at least for forest-dwelling passerines in the western Hemisphere. Yet, despite

88 longstanding interest in the idea of a latitudinal gradient in survival, we still lack an empirical

89 synthesis at the global scale, which stands as a limiting factor in our ability to generalize these

90 relationships to the diverse life history of birds found worldwide (Martin 2004).

92 consistent latitudinal variation in survival and other life history traits with which it covaries, such 
93 as clutch size (Karr et al. 1990; Faaborg \& Arendt 1995; Johnston et al. 1997; Peach et al. 2001;

94 McGregor et al. 2007). Indeed, most comparative studies of variation in life history traits treat

95 northern and southern latitudes equivalently (Jetz et al. 2008; Muñoz et al. 2018; Terrill 2018).

96 However, this assumption may not always be met, since latitude itself does not directly influence

97 organisms per se; rather, environmental factors that covary with latitude (i.e., temperature,

98 precipitation, seasonality) exert selective pressures on life history traits. For example, although

99 there exists a global latitudinal gradient in clutch size (Cardillo 2002; Jetz et al. 2008), this trend

100 is dampened in the southern hemisphere-south temperate species lay smaller clutches than

101 those in the north temperate hemisphere (Yom-Tov et al. 1994; Martin 1996; Evans et al. 2005).

102 Consistent with this pattern, south temperate birds in Africa also tend to be longer lived than

103 their north temperate European counterparts (Lloyd et al. 2014). This hemispheric asymmetry

104 may in part be due to differing climatic conditions between northern latitudes and equivalent

105 southern ones. Namely, south temperate latitudes are less seasonal and have higher minimum

106 winter temperatures, both of which have been hypothesized to decrease adult mortality and lead

107 to smaller clutch size (Ricklefs 1980; Martin 2004). Similarly, clades and their intrinsic traits that

108 may influence survival rates are also distributed nonrandomly across environmental gradients

109 (Jetz et al. 2008; Sibly et al. 2012). Migratory habit, for instance, arises at least in part from

110 species occupying higher latitudes and experiencing seasonal environments with lower minimum

111 winter temperatures, and there can be substantial deleterious effects on survival over the

112 migratory phase of the annual cycle (Sillett \& Holmes 2002; Rockwell et al. 2017). Thus, the

113 geographic variation in survival rates reflects a composite of extrinsic factors, intrinsic traits, and

114 historical events related to a species' lineage.

115 Because previous analyses of the latitudinal gradient in survival have focused on the 
117 group of taxa, our current perspective of the biological underpinnings of the geographic variation

118 in survival rates remains somewhat limited. Here, we present data on survival rates for 679

119 species of landbirds gathered from across the globe (Fig. 1). The purpose of our meta-analysis

120 was to test the relative importance of latitude and extrinsic climate factors (temperature,

121 precipitation, and seasonality) in explaining geographic patterns of avian survival rates, and to

122 ask whether including intrinsic traits (body mass, clutch size, migratory habit) improved model

123 predictions. Specifically, we ask: (1) Is there a latitudinal gradient in adult survival and, if so, are

124 there differences between hemispheres? (2) Do climate measurements (extrinsic factors) explain

125 differences in survival rates as well as latitude? (3) Do intrinsic traits explain additional variation

126 in species-level survival rates? We tested for these relationships in both nonpasserines and

127 passerines and between Old World and New World birds from island and mainland populations.

128 By integrating data on macroecological processes with comparative biology, our modeling

129 approach provides a powerful tool for understanding the diversity of life histories that have

130 evolved across the globe.

131

\section{METHODS}

\section{Assembling a global dataset of avian survival rates}

134 We conducted an extensive search of the peer-reviewed literature for studies that measured

135 survival rate in bird populations, relying primarily on Web of Science Core Collections

136 (http://apps.webofknowledge.com/) and Google Scholar (https://scholar.google.com/). We also

137 included data for survival rates of North American birds downloaded from the Monitoring Avian

138 Productivity and Survivorship (MAPS) program (www.vitalratesofnorthamericanlandbirds.org; 
139 DeSante et al. 2015). We searched online using combinations of the following terms: 'survival',

140 'mortality', 'vital rate', or 'demography', and 'bird' or 'avian'. Our initial survey resulted in over

1412000 publications. We then screened titles and abstracts of publications and considered them for

142 final inclusion in the meta-analysis if they met the following criteria: (1) the study provided

143 estimates of adult survival, not juvenile or nestling, at the species level. (2) The species studied

144 was not pelagic. (3) The study did not include harvested or captive-bred populations, whose

145 survival rates may not reflect those experienced under natural conditions. (4) Survival rate was

146 estimated on the breeding grounds (i.e., we did not include estimates from studies of over-

147 wintering or migratory stopover sites). (5) The data were collected from marked populations of

148 birds to estimate apparent or true survival using one of three methods: live-recovery/resight

149 models, dead-recovery models, or more complex models that used a combination of these two

150 approaches. (6) The study was conducted for at least 3 years, which is the minimum number of

151 occasions needed to estimate the probability of encounter $(p)$ from live-encounter data

152 (Sandercock 2006). To avoid sex-biased differences in survival probability (Székely et al. 2014),

153 we also required that (7) the estimate of survival included data from both males and females. In

154 cases when studies had overlapping data, we retained the publication that presented the most

155 information (i.e., had more precise estimates or used a larger dataset). This second review

156 narrowed the window of appropriate publications to 319. However, many of these papers did not

157 report measurement error on survival rate, which is required to weight individual effect sizes in

158 meta-analyses. Our final dataset therefore consisted of 246 publications (Appendix 1), which we

159 examined in detail and extracted relevant data.

160 For each publication, we extracted information on species' annual survival rates and their

161 standard error. Some studies (e.g., Collingham et al. 2014) presented standard error of logit 
162 survival. In these cases, we used a first order Taylor expansion to approximate precision. When

163 the same study provided separate estimates for males and females, or where estimates were made

164 for different time periods, ages of adult birds, or circumstances (e.g., successful breeders vs.

165 unsuccessful, brood parasites present vs. absent) we took the geometric mean of those estimates.

166 When estimates were available from different habitat types within the same study (e.g., logged

167 vs. unlogged forest), we took the geometric mean of those estimates, provided that the study

168 found no significant differences between groups. If group estimates were reported as

169 significantly different, we chose the estimate from the control group for our analysis. We also

170 recorded information on publication identity, species identity and the method used to estimate

171 adult survival.

172

173 Calculating the latitudinal gradient and global climate data

174 In order to assess the relationship between survival and latitude, we recorded the geographic

175 coordinates for each species in each study from information provided in the paper itself or by

176 locating the study area on Google Maps (google.com/maps). For 26 studies that measured

177 survival over broad spatial scales, such as at the national or continental level (e.g., the MAPS

178 dataset; DeSante et al. 2015), we calculated the centroid of the breeding range for each species

179 within the area specified by the study with occurrence data extracted from eBird using the $R$

180 package auk (Strimas-Mackey et al. 2018). This allowed us to estimate a unique latitude and

181 longitude for the centroid of each species' realized breeding range rather than simply selecting an

182 unweighted point in the study area itself. For each target region, we extracted eBird observations

183 submitted over the last 15 years during the breeding period (May 1-August 8 for birds from

184 Canada, the United States, and Europe, and September 1-December 8 for species from South 
Africa). We further filtered data to include only complete eBird checklists (i.e. those where users specify that all species seen or heard are reported), which allowed us to identify implicit non-

187 detections for each species, and by stationary counts $<24$ hours, traveling counts $<25 \mathrm{~km}$, and

188 area counts within a circle of radius $25 \mathrm{~km}$. We then overlaid the eBird checklists with a $25 \mathrm{~km}$

189 equal-area raster grid and calculated the frequency of occurrence of each species on checklists

190 within each grid cell. We took a weighted average of the grid-cell centers, using the species

191 observation frequency as the weight, and used the geographic coordinates of this centroid to

192 represent the species-site specific latitude. Because latitude is often used as a surrogate for

193 variation in climatic conditions between the north and south poles, we also evaluated the

194 predictive power of three key extrinsic factors that characterize the environment of a species and

195 are hypothesized to influence survival rates: annual precipitation (Wolfe et al. 2015, Shorgen et

196 al. 2019), minimum winter temperature (Robinson et al. 2007; Salewski et al. 2013), and

197 seasonality (Ricklefs 1980, Martin 2004). We downloaded information on climate measurements

198 from WorldClim Global Climate Data (worldclim.org) averaged over 1970-2000 (Fick and

199 Hijmans 2017) at 2.5-minute spatial resolution. We extracted data for total annual precipitation

200 (Precip, mm), minimum temperature of the coldest month $\left(\right.$ Temp $\left.{ }_{\text {Winter }},{ }^{\circ} \mathrm{C}\right)$ and calculated

201 temperature seasonality (Temp $\left.p_{\text {Seasonality, }}{ }^{\circ} \mathrm{C}\right)$ following Jetz et al. (2008) as the difference between

202 mean summer and winter temperatures averaged over 3-month periods.

203

204 Clutch size, body mass, and migratory behavior at a global scale

205 To test additional hypotheses of intrinsic factors that may explain global patterns in avian

206 survival rates, we collected data on body mass, clutch size, and species' migratory habit. We

207 obtained body mass (measured in grams) from information contained in the paper, or from the 
209 et al. 2018). Similarly, we extracted data on clutch size when it was presented in the paper itself

210 and used published standard reference databases (Jetz et al. 2008; del Hoyo et al. 2018) when it

211 was not. Following del Hoyo et al. (2018), we classified species as either migratory or non-

212 migratory. We considered migratory species to be those that regularly undertook seasonal

213 movements $>100 \mathrm{~km}$ (i.e., short- and long-distance migrants). While some species do not clearly

214 conform to this dichotomy, it is useful way to contrast important sources of mortality that could

215 influence survival rates.

\section{Statistical analysis}

218 Before conducting analyses, we $\log _{10}$ transformed mass and clutch size due to skewness, and

219 scaled latitude and climate data to $\mathrm{z}$ scores by subtracting their mean and dividing by their

220 standard deviation. Most variables were weakly correlated, although both measures of

221 temperature reached Spearman rank correlations $>0.75$ (Table S1). To estimate adult survival

222 rates along the latitudinal gradient, we used a multi-level meta-analytical framework using the

223 metafor package (Viechtbauer 2010), which fits random and fixed effects models, weighting

224 effect sizes by the inverse of their squared standard error. For each model developed, we

225 accounted for sources of non-independence in our dataset that can arise when multiple survival

226 estimates are extracted from the same study, are available for the same species, and / or due to

227 common ancestry, by fitting publication identity, species identity, and phylogeny as random

228 intercepts. To incorporate phylogeny, we used a majority rules consensus tree derived from a set

229 of 1,000 randomly-selected trees based on the global phylogeny of birds (Jetz et al. 2012), and

230 pruned to our study taxa (Fig. S1) with the package phytools (Revell 2012). We then used the 
231 branch length from this consensus tree to specify values for the model variance-covariance

232 matrix. We performed all statistical analyses in $R$ environment 3.5.0 (R Core Team 2019).

234 Meta-analyses and meta-regressions

235 We first ran a random effects only model on the entire dataset using the rma.mv function to

236 estimate a pooled effect size of global avian survival rates. Given potential differences in

237 selection pressures experienced by nonpasserines vs. passerines, species from Old World

238 (Afrotropics, Indomalayan, Palearctic) vs. New World (Neotropics, Nearctic) biogeographic

239 realms (Olson et al. 2001), and island vs. mainland bird populations, we also evaluated separate

240 meta-analytic models using effect sizes for these six data subsets. We considered point estimates

241 to be different from one another if their 95\% confidence intervals (CI) did not overlap. We

242 quantified total heterogeneity of each dataset by calculating Cochran's $Q$ and the $I^{2}$ statistic

243 (Higgins \& Thompson 2002).

244 We conducted meta-regressions (meta-analyses incorporating explanatory variables,

245 hereafter referred to as "moderators") whereby we determined the effects on species-specific

246 adult survival rates of (1) latitude, (2) extrinsic climatic factors, and (3) intrinsic traits in

247 accordance with hypotheses described from the primary literature. We began by comparing fit of

248 a latitude-only model (Latitude), where regression slopes varied between hemispheres, to single-

249 predictor linear models testing the influence of moderators on adult survival rates (Table S2). We

250 next used $\mathrm{AIC}_{\mathrm{C}}$ values (AIC corrected for small sample size, Burnham \& Anderson 2002) to

251 guide selection of a multi-predictor model of extrinsic climatic factors and intrinsic traits

252 separately, and then combined both sets of moderators with Latitude into a joint model. Starting

253 with the moderator that had the lowest $\mathrm{AIC}_{\mathrm{C}}$ value, we sequentially added the next strongest 
254 moderator until $\mathrm{AIC}_{\mathrm{C}}$ was no longer improved. We considered the model that minimized $\mathrm{AIC}_{\mathrm{C}}$

255 the most appropriate if it had fewer parameters and was at least $2 \mathrm{AIC}_{\mathrm{C}}$ less than the next most

256 competitive model (Arnold 2010). All of the intrinsic moderators we assessed improved model

257 fit (Table S3) and were carried forward to the next step of model development. Temp $p_{\text {seasonality }}$

258 provided the best model fit for extrinsic moderators; neither annual precipitation nor winter

259 temperature improved $\mathrm{AIC}_{\mathrm{C}}$ values during construction of the multi-predictor extrinsic model.

260 We repeated analysis of the joint extrinsic / intrinsic model for each of the six data subsets.

\section{Sensitivity analyses and publication bias}

263 To test whether our results were sensitive to differences in the study method used to estimate

264 survival, we fit additional models with study type as a moderator. We also repeated analyses

265 comparing separate datasets for effect sizes where we used package auk to calculate the

266 geographic coordinates versus those where we did not, and again using only those studies that

267 reported survival estimates for less than 10 species, and those that were conducted for a

268 minimum of 10 years. We tested for publication bias of the entire dataset, which can result from

269 selective publication of favorable or statistically significant results, by visually assessing

270 asymmetry of funnel plots.

271

272 RESULTS

273 Our final dataset consisted of 1004 effect sizes that we extracted from 246 publications for 679

274 species (Fig. 1; Appendix S1). The majority of effect sizes (82\%) came from passerine birds, and

275 effect sizes obtained from the New World biogeographical realms (282 Nearctic and 297

276 Neotropical) were more numerous than those from Old World studies $(176,169$, and 51 of effect 
277 sizes from the Palearctic, Afrotropical, and Indomalayan realms, respectively; Fig. S2).

278 Approximately twice as many estimates were available from studies conducted in the northern

279 hemisphere $(n=681)$ compared to the southern hemisphere $(n=323)$. The majority of effect

280 sizes reported per study was 1 (geometric mean $=1.6, S D=12.4$ ) and multiple estimates for the

281 same species were available from different studies for 168 species, accounting for $49 \%$ of all

282 effect sizes included in the analysis.

\section{Meta-analytic means and the relationships between intrinsic and extrinsic variables}

285 The meta-analytic mean calculated for the full dataset was 0.66 (95\% CI $=0.48$ to 0.85 ; Table

286 S4). This represents the overall global mean survival rate for all birds included in our analysis.

287 The joint model explained variation in survival well (Fig. S3; $x_{\text {Observed }}=0.40+0.38$ (residual

288 standard error $=0.07) x_{\text {Predicted }} ; F_{1,1004}=738.6$; adjusted $\left.r^{2}=0.42\right)$. When we estimated separate

289 meta-analytical means for the six data subsets, we found similar values with overlapping 95\%

290 confidence intervals between the global mean and mean effect sizes calculated for nonpasserines

291 vs. passerines, Old World vs. New World biogeographical realms, and estimates from islands vs.

292 mainland birds (Fig. 2; Table S4). In addition, all models had values of $P<0.0001$ for QE and

$293 I^{2}>90 \%$, which indicated that substantial heterogeneity remained unexplained among studies and

294 warranted our subsequent step of evaluating moderator variables.

295 We found evidence supporting the hypothesis of a latitudinal gradient in survival, and

296 this effect was most apparent in the northern hemisphere (Figs 3 and 4). When we examined

297 model predictions from a single-predictor model of latitude over the entire dataset, survival

298 decreased by $2 \%$ for every $10^{\circ}$ increase in latitude for species in the northern hemisphere

299 compared to a $<1 \%$ decrease for southern hemisphere species (Fig. 3A). Similarly, estimates 
300 from the joint model based on the entire dataset showed a significant negative effect of latitude

301 on survival for northern hemisphere species $(\beta=-0.039,95 \% \mathrm{CI}=-0.072$ to -0.006$)$, but not for

302 those inhabiting the southern hemisphere $(\beta=-0.004,95 \% \mathrm{CI}=-0.026$ to 0.019 ; Table 1$)$.

303 Driving this global trend at northern latitudes were significant negative point-estimates for

304 passerine birds $(\beta=-0.064,95 \% \mathrm{CI}=-0.103$ to -0.025$)$ and species $/$ populations from the

305 mainland $(\beta=-0.046,95 \% \mathrm{CI}=-0.080$ to -0.012 ; Fig. 4). In contrast, effect sizes calculated for

306 southern latitudes were smaller and the overall slope of the meta-regression line of the global

307 model was shallower compared to the northern hemisphere (Figs 3A and 4). Only New World

308 species (i.e., birds from South America) showed a significant negative association with latitude

$309(\beta=-0.055,95 \% \mathrm{CI}=-0.090$ to -0.021 ; Fig. 4$)$. Of the extrinsic climate moderators we

310 considered, temperature seasonality was the most competitive within our AIC model selection

311 framework (Table S2 and S3), although only marginally so compared to minimum winter

312 temperature. Regardless of which climate moderator was used in the joint model, the effect

313 calculated over the global dataset was nonsignificant (Fig. 3B) and all other data subsets had

314 effect sizes close to and confidence intervals overlapping zero.

315 In general, the relationship between survival and intrinsic life history characteristics was

316 stronger than those of either climate or latitude (Table 1; Fig. 4). Effect size estimated from the

317 global model was positive for mass $(\beta=0.053,95 \% \mathrm{CI}=0.043$ to 0.063$)$ and negative for clutch

318 size $(\beta=-0.101,95 \% \mathrm{CI}=-0.128$ to -0.074$)$, which means that avian survival was higher for

319 larger birds and for those with smaller clutch sizes (Figs 4C and D). With the exception of mass

320 for island species, similar results for both moderators were found for all data subsets, supporting

321 the previously well documented relationship between mass and clutch size and survival (Fig. 4).

322 When we included migration as a moderator in the meta-regression on the full data set, the effect 
323 size was small and positive, with confidence intervals marginally overlapping zero $(\beta=0.016$,

$32495 \% \mathrm{CI}=-0.005$ to 0.039 ; Fig. $3 \mathrm{E})$. Although the relative effect of migration varied some

325 between data subsets, all but Old World birds $(\beta=0.037,95 \% \mathrm{CI}=0.004$ to 0.070$)$ had

326 confidence intervals that included zero, suggesting higher survival for nonmigratory birds in

327 Africa and Asia (Fig. 4).

328

329 Sensitivity analysis

330 When we estimated mean survival for effect sizes calculated from studies using capture-mark-

331 recapture methods, dead recovery methods, or complex models that integrated a combination of

332 these two approaches, we found point estimates were not distinguishable from the overall mean

333 (Fig. 5). Similarly, when we removed data where we used the package auk to calculate latitude

334 and longitude, or when we removed the 22 studies reporting estimates for $>10$ species (which

335 accounted for nearly $64 \%$ of all effect sizes) the results were qualitatively similar to the global

336 mean survival rate based on the entire dataset (Fig. 5). We found no indication of publication

337 bias after examining symmetry of funnel plots (Fig. S4).

\section{DISCUSSION}

\section{Global-scale patterns of avian survival with latitude}

341 We found support for the oft-toted latitudinal-survival gradient, but this depended on both the

342 geographic area and taxa being considered. Specifically, we demonstrate that the previously

343 noted inverse relationship between latitude and survival is borne out across northern hemisphere

344 avifauna overall, and that this effect is strengthened when considering only passerines or species

345 inhabiting the mainland (Fig. 4). In contrast, the relationship was only evident in the southern 
346 hemisphere for survival estimates from New World birds (Fig. 4), the vast majority of which

347 were passerines. When considered independently, there was no indication that nonpasserines had

348 higher survival with decreasing latitude in either hemisphere. Overall, our meta-analysis reveals

349 that while some tropical birds may be longer lived than their temperate counterparts, the shape of

350 the latitude-survival response is likely to differ among species and between hemispheres.

351 Our synthesis is the first to assess global-scale patterns in avian survival rates; previous

352 studies have either been limited geographically (Karr et al. 1990; Peach et al. 2001; Lloyd et al.

353 2014), or have focused on a narrower range of species, such as raptors (Newton et al. 2016) or

354 shorebirds (Méndez et al. 2018). To date, the most extensive analysis of avian survival and

355 latitude comes from a study of 12 locations spanning $60^{\circ}$ across the Americas (Muñoz et al.

356 2018). Our global-scale analysis compliments that of Muñoz et al. (2018), who reported a linear

357 decrease in survival of roughly $2.1 \%$ for every $10^{\circ}$ increase in latitude for passerine birds from

358 Alaska to Peru, nearly identical to what we observed for northern hemisphere species worldwide.

359 Granted both our studies used a meta-analytical approach, Muñoz et al. (2018) conducted their

360 analysis using a Bayesian mode of inference and considered only forest-dwelling passerines,

361 while our study includes survival estimates of both passerines and nonpasserines from a variety

362 of habitats, which we investigated using a maximum-likelihood approach. We also fit regression

363 lines for latitude both north and south of the equator rather than testing the relationship between

364 survival and absolute latitude. This latter point is particularly important, given that one general

365 explanation for spatial patterns in life-history traits is that they arise from natural selection

366 imposed by latitudinal gradients in environmental conditions (Cardillo 2002), which differ

367 between hemispheres (Chow et al. 2004). Despite our use of different methods, the fact that we

368 obtained some common results lends increased support to the overall relationship. Moreover, 
369 with our analysis, we provide a stronger mechanistic basis for understanding variation in survival

370 rates, as it better reflects the climatic variables that underlie latitude in the northern and southern

371 hemispheres.

372 Hemispheric asymmetries in other patterns of avian life-history traits, such as timing of

373 reproduction (Covas et al. 1999), clutch size (Moreau 1944; Martin et al. 2006; Lloyd et al.

374 2014), and parental care (Russell 2000; Russell et al. 2004; Llambías et al. 2015), are well

375 documented. The global patterns we identified are also congruent with the idea of a differential

376 response of life-histories between hemispheres - we detected an inverse relationship between

377 survival and latitude in the northern hemisphere but found little indication that this association

378 was mirrored by southern hemisphere species overall. Only when we analyzed biogeographic

379 realms in the southern hemisphere separately did we find that New World birds showed higher

380 survival with decreasing latitude. This pattern is deceptive, however, since southern hemisphere

381 nonpasserines account for little more than $1 \%$ of the effect sizes analyzed in the New World data

382 subset. We therefore interpret this result as evidence of the latitudinal-survival gradient in South

383 American passerines. This means that for Old World birds, tropical species had similar survival

384 rates to birds from the austral zone, and this was likely to be true regardless of whether they were

385 passerines or nonpasserines. Survival estimates from Australasia and Oceania, biogeographic

386 realms not traditionally included in the New / Old world classification, also reflected this same

387 pattern and showed no evidence of a negative relationship with latitude.

Such differences may be explained, in part, by the historical geography and latitudinal

389 positions of the continents. For the last 15 million years, South America has extended roughly

$39020^{\circ}$ further into the southern hemisphere than continental landmasses in the Old World. Thus,

391 one reason we may have detected a negative trend in survival for southern hemisphere birds, but 
392 only in the New World, could simply be due to the greater range of latitudes and climatic

393 conditions available to landbirds from South America with which to adapt. For example,

394 latitudes greater than $35^{\circ} \mathrm{S}$ are characterized by higher seasonality and mean annual

395 temperatures $\leq 0^{\circ} \mathrm{C}$ (Chown et al. 2004); thus, this result may be indicative of a threshold

396 response of avian survival to freezing temperatures and / or a more seasonal environment.

397 Supporting this idea, mean survival of South American passerines that occurred at latitudes

398 higher than $35^{\circ} \mathrm{S}$ (survival rate $=0.38, \mathrm{n}=8$ ) was lower on average than those from the highest

399 latitudes occupied by birds in Africa (Old World survival at $34^{\circ} \mathrm{S}=0.69, \mathrm{n}=19$ ). Only one

400 other study has addressed the question of a latitudinal-survival gradient in the southern

401 hemisphere; Lloyd et al. (2014) found no indication of higher survival for birds living in tropical

402 Malawi compared to austral South Africa. Our results are congruent with those findings and

403 suggest that higher survival of tropical birds may be a pattern localized primarily to passerines

404 from the northern hemisphere and in South America, where factors such as a more seasonal

405 environment may limit resource availability and constrain species survival.

\section{Influence of Climate on Survival}

408 Our results suggest that temperature seasonality, at least at the resolution at which we examined

409 it, is a poor predictor of avian survival. Indeed, latitude-only models out performed single-

410 predictor models of extrinsic climate factors for each of the moderators we considered by a

411 minimum of $>8 \Delta \mathrm{AIC}_{\mathrm{C}}($ Table $\mathrm{S} 2)$. Although temperature seasonality was not significant, our

412 finding of higher survival in the southern hemisphere, but only for New World birds is in

413 accordance with reported asymmetries in climate between hemispheres. Compared to north-

414 temperate latitudes, austral latitudes are characterized as less seasonal in general, having higher 
415 minimum winter temperatures and higher, less variable patterns of precipitation (Chown et al.

416 2004). That said, South America does posses environments with climates closer to those of the

417 northern hemisphere (e.g., mean temperatures $\leq 0^{\circ} \mathrm{C}$, higher temperature seasonality) compared

418 to Africa and Asia, which lack such climate analogs at their southern-most latitudes. Although

419 latitudinal variation in life history traits arises in part from natural selection imposed by complex

420 interactions among environmental factors, latitude as a 'catch-all' variable provided a more

421 complete picture of global variation in survival. For example, temperature seasonality fails to

422 capture the negative latitude-survival relationship in passerines because this effect is counter-

423 acted by pooling data for taxa from different regions; specifically, combining data with estimates

424 for southern hemisphere passerines from the Old World. It appears, therefore, that latitude

425 remains one of the best methods to portray the suite of climatic constraints that characterize a

426 species' environment and leads to variation in life histories, but only when northern and southern

427 hemispheres are examined independently.

429 Intrinsic traits mediate variation in the latitudinal survival gradient

430 We find that the association between body mass and survival and reproduction and survival -

431 two of the cornerstone trade-offs of life history theory (Stearns 1992) — are well supported by

432 our meta-analysis, suggesting higher survival for larger birds and those with smaller clutch sizes

433 (Fig 3C and D). Notably, when mass and clutch size were included in the joint model, the

434 strength of the latitudinal survival gradient was diminished (Table 1; Fig 3). In contrast, we

435 found the addition of migratory habit to be generally negligible (Fig 3). These results highlight

436 the importance of considering the interplay between intrinsic and extrinsic variables when

437 investigating macroecological processes. Latitude of course influences many aspects of avian life 
438 history, including both clutch size (Cardillo 2002; Jetz et al. 2008) and body mass (Olson et al.

439 2009), both of which have been demonstrated to increase globally with increasing latitude.

440 Additionally, median body size also decreases systematically within species-rich communities,

441 such as those characterized at many tropical latitudes (Olson et al. 2009). Combined with these

442 findings, our results are in accordance with the theory of a slow-fast life-history continuum

443 (Ricklefs \& Wikelski 2002) and suggest that while birds at tropical latitudes tend to be longer

444 lived and have reduced clutches given their body size, this is far from the full picture. Global

445 patterns of avian survival are driven by interactions between intrinsic traits and lineage-specific

446 effects of latitude and their associated climatic factors.

\section{Challenges in evaluating avian survival}

449 Adult survival estimates are affected by several methodological caveats that we consider here.

450 First, a general problem with comparing survival studies is that differences between estimates

451 derived from old versus new methods and between live recaptures and dead recoveries may mask

452 trends in the data (Roodbergen et al. 2012). Our dataset consisted primarily of studies that used

453 live capture-mark-recapture techniques (83\% of effect sizes) and most of these were conducted

454 since 2000; nearly all studies were conducted after 1990 when modern statistical tools for

455 analyses of marked animals were developed (Lebreton et al. 1992). One of the drawbacks of

456 capture-mark-recapture data is that the reported metric, apparent survival, is a product of true

457 survival and site fidelity and as such will always be biased low, whereas estimates of survival

458 from dead recovery models are often interpreted as true survival (Sandercock 2006). Biases in

459 survival estimates may therefore be strong for birds from tropical regions, which consisted

460 exclusively of live-recapture data, and where behaviors such as altitudinal migration are more 
461 common than in temperate regions (Barçante et al. 2017) and can lead to permanent emigration

462 from study plots. Another issue affecting the comparison of survival studies is the study duration.

463 This, too, may be particularly problematic for tropical regions, where data collection is often

464 hampered by sampling conducted over irregular or insufficiently long intervals to produce robust

465 estimates of survival (Ruiz-Guitérrez et al. 2012). For example, in our meta-analysis 62\% and

$466 \quad 69 \%$ of effect sizes from austral and temperate latitudes, respectively, were calculated from

467 datasets spanning > 10 years, compared to only $34 \%$ from tropical latitudes. However, in a study

468 of tropical birds comparing survival estimates derived from 6 vs.12 years of data, Blake \&

469 Loiselle (2013) reported an improvement in precision, but no change in point estimates for

470 survival. Still, other authors argue that longer time frames are needed to generate reliable

471 survival estimates for tropical resident species (i.e., 10-30 years), given their expected longevity

472 and low recapture probabilities ( $p<0.25$; Ruiz-Guitérrez et al. 2012). Despite these problems

473 with the comparability of the data, we found no indication that difference in methodological

474 approaches strongly biased our results (Fig. 5).

475

\section{CONCLUSION}

477 Based on a global-scale synthesis of avian survival rates, we find evidence that survival increases

478 with decreasing latitude, but that this phenomenon is more nuanced than previous descriptions

479 have characterized. Specifically, we demonstrate that the latitudinal survival gradient is stronger

480 in northern hemisphere species, where climate seasonality may be greater. By including aspects

481 of species life history characteristics in our models, we could explain a greater portion of the

482 variation in survival rates than with latitude alone. These results indicate the importance of

483 considering an organism's intrinsic traits as well as the extrinsic factors of their environment 
484 when describing broad-scale macroecological patterns. Where peaks in survival occur, how they

485 relate to climatic variables, and how these patterns are likely to change through time and space

486 given the effects of climate change, are of major importance for conservation. We hope that in

487 assembling this database and dissecting some of the global patterns in survival across avian

488 groups and hemispheres, we can provide a platform for future work to target underrepresented

489 regions and taxa and also make a clear path forward to better understanding variation in survival

490 rates, and how it intersects with other life history traits across the world's avifauna.

491

\section{ACKNOWLEDGEMENTS}

493 We thank Peter Arcese and Ben Freeman for comments on previous versions of this manuscript.

494 We would also like to thank Umesh Srinivasan for helping locate studies of avian survival

495 throughout the world. This research was supported by funding from the University of British

496 Columbia to M. N. Scholer, and by Discovery Grant F11-05365 from the Natural Sciences and

497 Engineering Research Council to J. E. Jankowski.

\section{REFERENCES}

500 Arnold, T.W. (2010). Uninformative parameters and model selection using Akaike's information 501 criterion. J. Wildl. Manage., 74, 1175-1178.

502 Barçante, L., M. Vale, M. \& Maria, M.A. (2017). Altitudinal migration by birds: A review of the 503 literature and a comprehensive list of species. J. F. Ornithol., 88, 321-335.

504 Bell, H.L. (1982). Survival among birds of the understorey in lowland rainforest in Papua New $505 \quad$ Guinea. Corella, 6, 77-82.

506 Blake, J.G. \& Loiselle, B.A. (2008). Estimates of apparent survival rates for forest birds in 
eastern Ecuador. Biotropica, 40, 485-493.

508

509

510

511

512

513

514

515

516

517

518

519

520

521

522

523

524

525

526

527

528

529

Blake, J.G. \& Loiselle, B.A. (2013). Apparent survival rates of forest birds in eastern Ecuador revisited: Improvement in precision but no change in estimates. PLoS One, 8, 8-13.

Burnham, K.P. \& Anderson, D.R. (2002). Model selection and multimodel inference: A practical information-theoretic approach. 2nd ed. Springer-Verlag, New York, NY.

Cardillo, M. (2002). The life-history basis of latitudinal diversity gradients: How do species traits vary from the poles to the equator? J. Anim. Ecol., 71, 79-87.

Chown, S.L., Sinclair, B.J., Leinaas, H.P. \& Gaston, K.J. (2004). Hemispheric asymmetries in biodiversity: A serious matter for ecology. PLOS Biol., 2, 1701-1707.

Collingham, Y.C., Huntley, B., Altwegg, R., Barnard, P., Beveridge, O.S., Gregory, R.D., et al. (2014). Prediction of mean adult survival rates of southern African birds from demographic and ecological covariates. Ibis (Lond. 1859)., 156, 741-754.

Covas, R., Lepage, D., Boix-Hinzen, C. \& du Plessis, M. (1999). Evolution of sociality and lifehistory strategies in birds: Confronting northern perspectives in the southern hemisphere. $S$. Afr. J. Sci., 95, 400-402.

DeSante, D.F., Kaschube, D.R. \& Saracco, J.F. (2015). Vital rates of North American Landbirds. Institue Bird Popul. Available at: www.VitalRatesOfNorthAmericanLandbirds.org. Last accessed 1 May 2019.

Dowsett, A.R.J. (1985). Site-fidelity and survival rates of some montane forest birds in Malawi south-central Africa. Biotropica, 17, 145-154.

Evans, K.L., Duncan, R.P., Blackburd, T.M. \& Crick, H.Q.P. (2005). Investigating geographic variation in clutch size using a natural experiment. Funct. Ecol., 19, 616-624.

Faaborg, J. \& Arendt, W.J. (1995). Survival rates of Puerto Rican birds: Are islands really that 
different? Auk, 112, 503-507.

531 Fogden, M.P.L. (1972). The seasonality and population dynamics of equatorial forest birds in

532 Sarawak. Ibis (Lond. 1859)., 114, 307-343.

533 Francis, C.M., Terborgh, J.S. \& Fitzpatrick, J.W. (1999). Survival rates of understorey forest

534 birds in Peru. In: Proceedings 22nd International Ornithological Congress, Durban, South

535 Africa,16-22 August 1998 (eds. Adams, N.J. \& Slotow, R.H.). BirdLife South Africa,

536 Johannesburg, South Africa, pp. 326-335.

537 Fry, C.H. (1980). Survival and longevity among tropical land birds. In: Proceedings of the 4th

538 Pan-African Ornithilogical Congress, Mahé, Seychelles, 6-13 May 1976 (ed. Johnson,

539 D.N.). Southern African Ornithological Society, Johannesburg, South Africa, pp. 333-343.

540 Ghalambor, C.K. \& Martin, T.E. (2001). Fecundity-survival trade-offs and parental risk-taking in

$541 \quad$ birds. Science (80-. )., 292, 494-497.

542 Healy, K., Guillerme, T., Finlay, S., Kane, A., Kelly, S.B.A., McClean, D., et al. (2014).

543 Ecology and mode-of-life explain lifespan variation in birds and mammals. Proceedings.

$544 \quad$ Biol. Sci., 281, 20140298.

545 Higgins, J.P.T. \& Thompson, S.G. (2002). Quantifying heterogeneity in a meta-analysis. Stat.

$546 \quad$ Med., 21, 1539-1558.

547 del Hoyo, J., Elliott, A., Sargatal, J., Christie, D. \& E, de J. (2018). Handbook of the Birds of the $548 \quad$ World Alive.

549 Jetz, W., Sekercioglu, C.H. \& Böhning-Gaese, K. (2008). The worldwide variation in avian

$550 \quad$ clutch size across species and space. PLOS Biol., 6, e303.

551 Jetz, W., Thomas, G.H., Joy, J.B., Hartmann, K. \& Mooers, A.O. (2012). The global diversity of

552 birds in space and time. Nature, 491, 444-448. 
553 Johnston, A., Robinson, R.A., Gargallo, G., Julliard, R., van der Jeugd, H. \& Baillie, S.R. (2016).

554 Survival of Afro-Palaearctic passerine migrants in western Europe and the impacts of

555 seasonal weather variables. Ibis (Lond. 1859)., 158, 465-480.

556 Johnston, J.P., White, S.A., Peach, W.J. \& Gregory, R.D. (1997). Survival rates of tropical and

557 temperate passerines: A Trinidadian perspective. Am. Nat., 150, 771-789.

558 Karr, J.R., Nichols, J.D., Klimkiewicz, M.K. \& Brawn, J.D.J.D. (1990). Survival rates of birds of

559 tropical and temperate forests: Will the dogma survive? Am. Nat., 136, 277-291.

560 Krementz, D.G., Sauer, J.R. \& Nichols, J.D. (1989). Model-based estimates of annual survival

561 rate are preferable to observed maximum lifespan statistics for use in comparative life-

562 history studies. Oikos, 56, 203-208.

563 Lack, D. (1947). The significance of clutch-size. Ibis (Lond. 1859)., 89, 302-352.

564 Lebreton, J.-D.D., Burnham, K.P., Clobert, J. \& Anderson, D.R. (1992). Modeling survival and 565 testing biological hypotheses using marked animals: A unified approach with case studies. 566 Ecol. Monogr., 62, 67-118.

567 Linden, M. \& Møller, A.P. (1989). Cost of reproduction and covariation of life history traits in $568 \quad$ birds. Trends Ecol. Evol., 4, 367-371.

569 Lindstedt, S.L. \& Calder, W.A. (1976). Body size and longevity in birds. Condor, 78, 91-94.

570 Lindstedt, S.L. \& Calder, W.A. (1981). Body size, physiological time, and longevity of

571 homeothermic animals. Q. Rev. Biol., 56, 1-16.

572 Llambías, P.E., Carro, M.E. \& Fernández, G.J. (2015). Latitudinal differences in life-history

573 traits and parental care in northern and southern temperate zone House Wrens. J. Ornithol., $574 \quad 156,933-942$.

575 Lloyd, P., Abadi, F., Altwegg, R. \& Martin, T.E. (2014). South temperate birds have higher 
apparent adult survival than tropical birds in Africa. J. Avian Biol., 45, 493-500.

577 Maestri, M.L., Ferrati, R. \& Berkunsky, I. (2017). Evaluating management strategies in the

578 conservation of the critically endangered Blue-throated Macaw (Ara glaucogularis). Ecol.

$579 \quad$ Modell., 361, 74-79.

580 Martin, T.E. (1995). Avian life history evolution in relation to nest sites, nest predation, and

581 food. Ecol. Monogr., 65, 101-127.

582 Martin, T.E. (1996). Life history evolution in tropical and south temperate birds: What do we 583 really know? J. Avian Biol., 27, 263-272.

584 Martin, T.E. (2004). Avian life-history evolution has an eminent past: Does it have a bright

585 future? Auk, 121, 289-301.

586 Martin, T.E., Bassar, R.D., Bassar, S.K., Fontaine, J.J., Lloyd, P., Mathewson, H.A., et al.

587 (2006). Life-history and ecological correlates of geographic variation in egg and clutch 588 mass among passerine species. Evolution (N. Y)., 60, 390-398.

589 McGregor, R., Whittingham, M.J. \& Cresswell, W. (2007). Survival rates of tropical birds in $590 \quad$ Nigeria, West Africa. Ibis (Lond. 1859)., 149, 615-618.

591 McNab, B.K. (1994). Resource use and the survival of land and freshwater vertebrates on 592 oceanic islands. Am. Nat., 144, 643-660.

593 Méndez, V., Alves, J.A., Gill, J.A. \& Gunnarsson, T.G. (2018). Patterns and processes in 594 shorebird survival rates: A global review. Ibis (Lond. 1859)., 160, 723-741.

595 Moreau, R.E. (1944). Clutch-size: A comparative study, with special reference to African birds. $596 \quad$ Ibis (Lond. 1859)., 86, 286-347.

597 Muñoz, A.P., Kéry, M., Martins, P.V. \& Ferraz, G. (2018). Age effects on survival of Amazon 598 forest birds and the latitudinal gradient in bird survival. Auk, 135, 299-313. 
599

600

601

602

603

604

605

606

607

608

609

610

611

612

613

614

615

616

617

618

619

620

621

Murray, B.G. (1985). Evolution of clutch size in tropical species of birds. Ornithol. Monogr., 36, $505-519$.

Newton, I., McGrady, M.J. \& Oli, M.K. (2016). A review of survival estimates for raptors and owls. Ibis (Lond. 1859)., 158, 227-248.

Nichols, J.D. \& Pollock, K.H. (1983). Estimation methodology in contemporary small mammal capture-recapture studies. J. Mammal., 64, 253-260.

Olson, D.M., Dinerstein, E., Wikramanayake, E.D., Burgess, N.D., Powell, G.V.N., Underwood, E.C., et al. (2001). Terrestrial ecoregions of the world: A new map of life on earth. Bioscience, 51, 933-938.

Olson, V.A., Davies, R.G., Orme, C.D.L., Thomas, G.H., Meiri, S., Blackburn, T.M., et al. (2009). Global biogeography and ecology of body size in birds. Ecol. Lett., 12, 249-259.

Peach, W.J., Hanmer, D.B. \& Oatley, T.B. (2001). Do southern African songbirds live longer than their European counterparts? Oikos, 93, 235-249.

Promislow, D.E.L. (1993). On size and survival: Progress and pitfalls in the allometry of life span. J. Gerontol., 48, B115-B123.

R Core Team. (2019). R: A language and environment for statistical computing. Vienna, Austria. Revell, L.J. (2012). An R package for phylogenetic comparative biology (and other things). Methods Ecol. Evol., 3.

Ricklefs, R.E. (1977). On the evolution of reproductive strategies in birds: Reproductive effort. Am. Nat., 111, 453-478.

Ricklefs, R.E. (1980). Geographical variation in clutch size among passerine birds: Ashmole’s hypothesis. Auk Ornithol. Adv., 97, 38-49.

Ricklefs, R.E. (2000). Density dependence, evolutionary optimization, and the diversification of 
avian life histories. Condor, 102, 9-22.

623 Ricklefs, R.E. \& Wikelski, M. (2002). The physiology/life-history nexus. Trends Ecol. Evol., 17, $624 \quad 462-468$.

625 Robinson, R.A., Baillie, S.R. \& Crick, H.Q.P. (2007). Weather-dependent survival: Implications 626 of climate change for passerine population processes. Ibis (Lond. 1859)., 149, 357-364.

627 Rockwell, S.M., Wunderle, J.M., Sillett, T.S., Bocetti, C.I., Ewert, D.N., Currie, D., et al. (2017).

628 Seasonal survival estimation for a long-distance migratory bird and the influence of winter 629 precipitation. Oecologia, 183, 715-726.

630 Roff, D. (2002). Life history evolution. Sinauer Associates, Sunderland, Massachusetts.

631 Roodbergen, M., van der Werf, B. \& Hötker, H. (2012). Revealing the contributions of 632 reproduction and survival to the Europe-wide decline in meadow birds: Review and meta633 analysis. J. Ornithol., 153, 53-74.

634 Ruiz-Guitérrez, V., Doherty, P.F., Santana, E.C., Contreras Martínez, S., Schondube, J., Verdugo 635 Munguía, H., et al. (2012). Survival of resident Neotropical birds: Considerations for 636 sampling and analysis based on 20 years of bird-banding efforts in Mexico. Auk, 129, 500637509.

638 Russell, E.M. (2000). Avian life histories: Is extended parental care the southern secret? Emu, $639 \quad 100,377-399$.

640 Russell, E.M., Yom-Tov, Y. \& Geffen, E. (2004). Extended parental care and delayed dispersal: 641 Northern, tropical, and southern passerines compared. Behav. Ecol., 15, 831-838.

642 Saether, B.-E. (1988). Pattern of covariation between life-history traits of European birds. Nature, 331, 616-617.

644 Salewski, V., Hochachka, W.M. \& Fiedler, W. (2013). Multiple weather factors affect apparent 
survival of European passerine birds. PLoS One, 8, e59110-e59110.

646 Sandercock, B.K. (2006). Estimation of demographic parameters from live-encounter data: A

647 summary review. Source J. Wildl. Manag., 70, 1504-1520.

648 Scholer, M.N., Arcese, P., Londoño, G.A., Puterman, M. \& Jankowski, J.E. (2019). Data from:

649 Survival is negatively related to basal metabolic rate in tropical Andean birds. Dryad Digit.

$650 \quad$ Repos.

651 Sibly, R.M., Witt, C.C., Wright, N.A., Venditti, C., Jetz, W. \& Brown, J.H. (2012). Energetics,

652 lifestyle, and reproduction in birds. Proc. Natl. Acad. Sci., 109, 10937-10941.

653 Sillett, T.S. \& Holmes, R.T. (2002). Variation in survivorship of a migratory songbird

654 throughout its annual cycle. J. Anim. Ecol., 71, 296-308.

655 Skutch., A.F. (1949). Do tropical birds rear as many young as they can nourish? Ibis (Lond.

656 1859)., 91, 430-455.

657 Snow, D.W. (1962). A field study of the Black and White Manakin, Manacus manacus, in 658 Trinidad. Zoologica, 47, 65-104.

659 Speakman, J.R. (2005). Body size, energy metabolism and lifespan. J. Exp. Biol., 208, 1717-

$660 \quad 1730$.

661 Stearns, S.C. (1992). The evolution of life histories. Oxford Univeristy Press, London.

662 Strimas-Mackey, M., Miller, E. \& Hochachka, W. (2018). auk: eBird Data Extraction and 663 Processing with AWK.

664 Terrill, R.S. (2018). Feather growth rate increases with latitude in four species of widespread 665 resident Neotropical birds. Auk, 135, 1055-1063.

666 Viechtbauer, W. (2010). Conducting meta-analyses in R with the metafor package. J. Stat. 667 Softw., 36, 1-48. 
668 Williams, G.C. (1966). Natural selection, the costs of reproduction, and a refinement of Lack's

669 principle. Am. Nat., 100, 687-690.

670 Wilman, H., Belmaker, J., Simpson, J., de la Rosa, C., Rivadeneira, M.M. \& Jetz, W. (2014).

671 EltonTraits 1.0: Species-level foraging attributes of the world's birds and mammals.

$672 \quad$ Ecology, 95, 2027-2027.

673 Yom-Tov, Y., Iglesias, G.J. \& Christie, M.I. (1994). Clutch size in passerines of southern South

674 America. Condor Ornithol. Appl., 96, 170-177.

675

676

677

678

679

680

681

682

683

684

685

686

687

688

689

690 
691

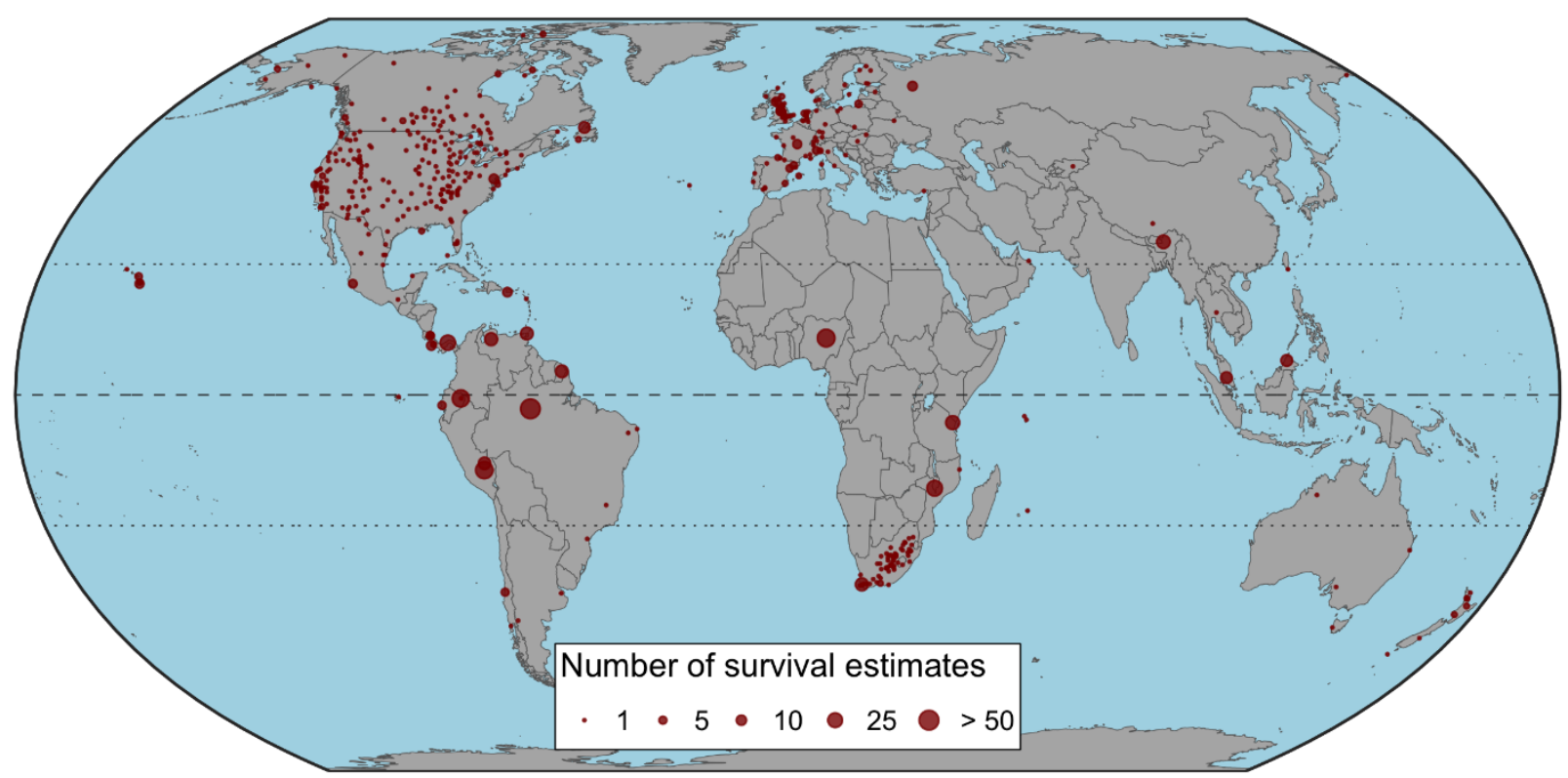

693 Figure 1 Location of effect sizes from 246 studies used in the meta-analysis of avian survival

694 rates. The number of survival estimates reported at each location is illustrated by the size of the

695 circle. Dashed line represents the equator while dotted lines at $23.4^{\circ} \mathrm{N}$ and $\mathrm{S}$ indicate the Tropic

696 of Cancer and Capricorn, respectively, and delineate the tropics. 
Meta-analytic mean, all data (1004)

$\underline{\text { Nonpasserine vs. Passerine: }}$

Nonpasserine (182)

Passerine (822)

Old world vs. New world:

Old world (396)

New world (579)

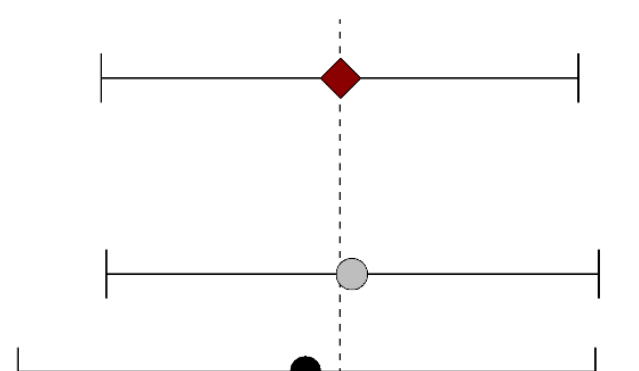

699

Figure 2 Mean avian survival and 95\% confidence limits calculated over the entire dataset and

700 from meta-regression models, which estimated intercepts independently for data from

701 nonpasserine vs. passerine birds, Old World vs. New World biogeographic realms, and islands

702 vs. mainland. Number of effect sizes used in each data subset are shown in parentheses. Dashed

703 line indicates the difference from the overall meta-analytical mean. 

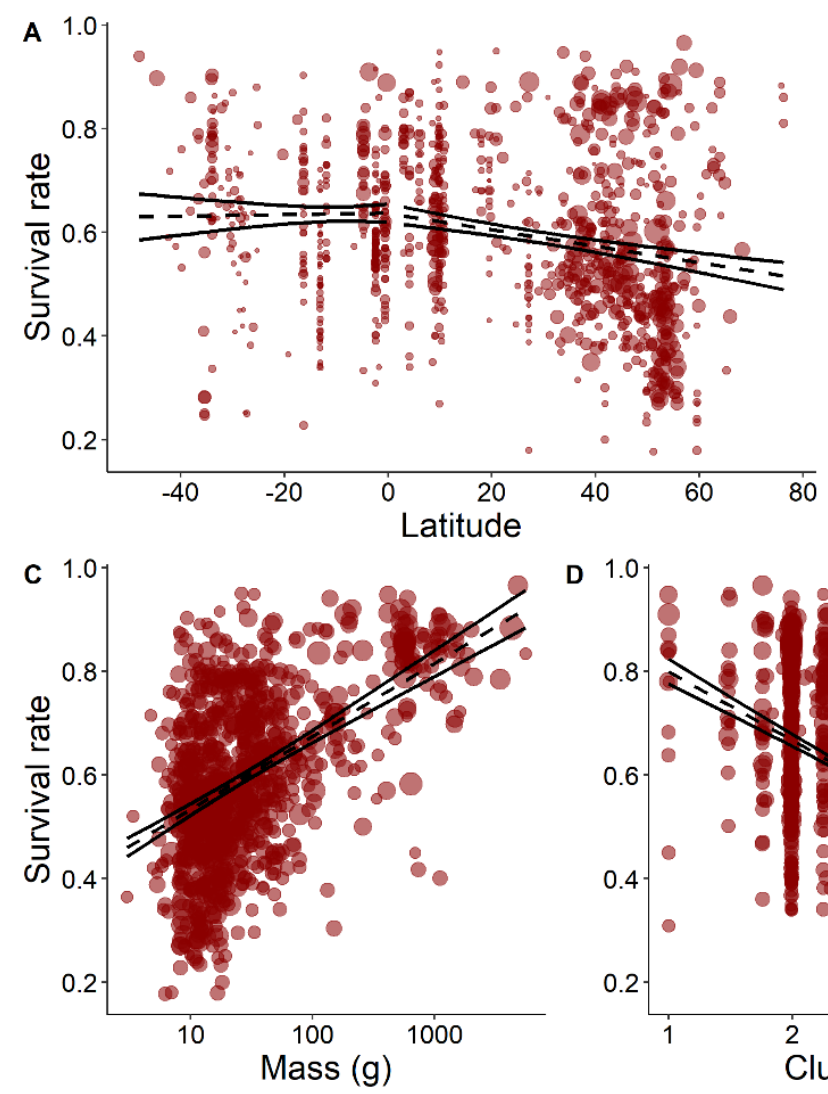

D 1.01
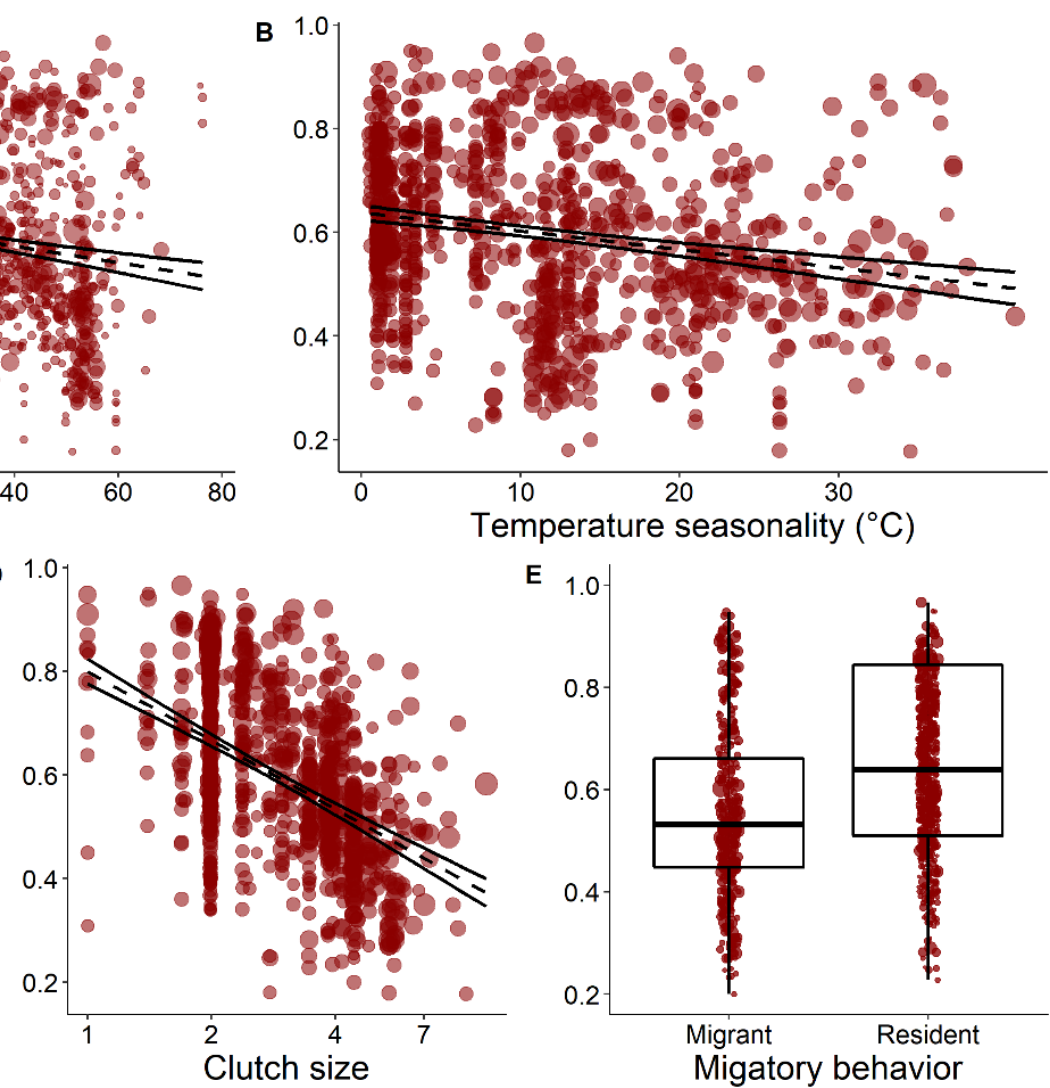

E 1.0

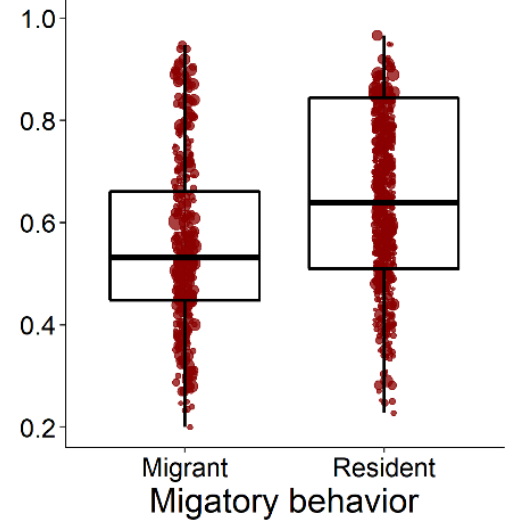

705 Figure 3 Relationship between adult survival rate of birds from the entire dataset and moderator

706 variables included in the joint extrinsic / intrinsic model (Table 1). Dashed lines represent the

707 best linear fit based on model predictions estimated from single-predictor meta-regression

708 models in metafor with $95 \%$ confidence intervals plotted as solid lines. Point sizes reflect the

709 inverse of the standard error used to weight data points (i.e., more precise estimates appear as

710 larger points). 


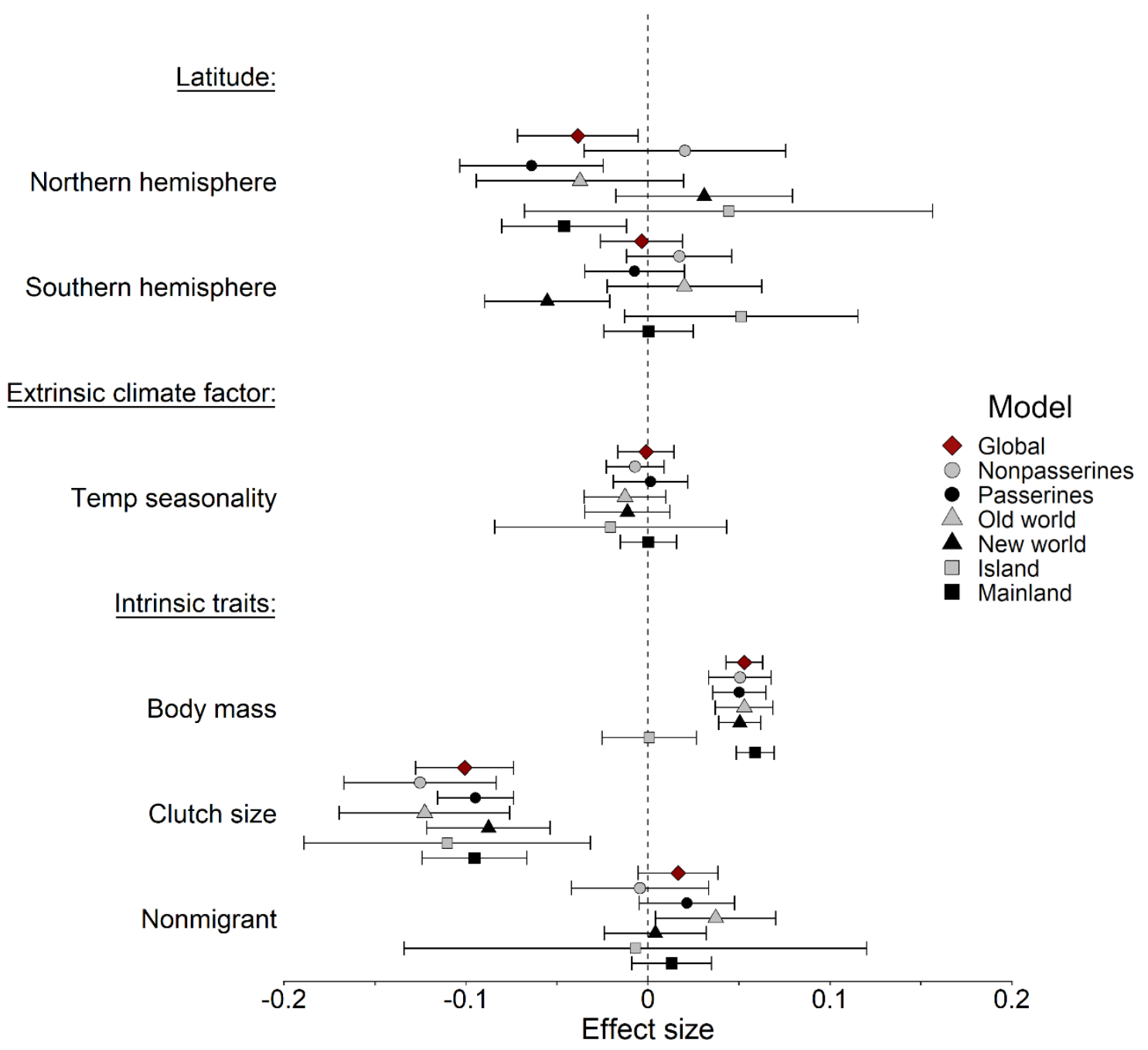

713 Figure 4 Overall effect sizes for the six variables considered in the joint extrinsic / intrinsic

714 model for the entire dataset and all data subsets. Bars indicate 95\% confidence limits. Effect

715 sizes are considered significant where confidence limits do not overlap zero (dashed line). 
Meta-analytic mean, all data (1004)

Meta-analytic mean, reduced model 1 (333)

Meta-analytic mean, reduced model 2 (603)

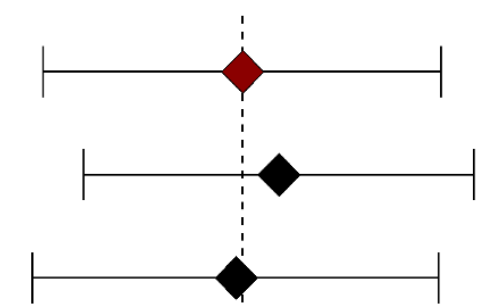

Study method:

CMR (830)

Dead recovery (79)

Complex (95)

Package AUK used:

Yes (292)

No (712)

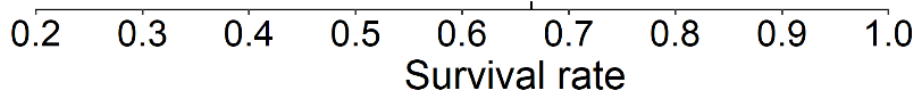

718 Figure 5 Results of the sensitivity analysis comparing the meta-analytic mean of the entire

719 dataset to a reduced dataset consisting of studies that reported $\leq 10$ effect sizes (reduced model

720 1), a reduced dataset consisting of studies that collected data for $\geq 10$ years (reduced model 2),

721 effect size estimated separately for each of three methods used to estimate survival, and effect

722 size calculated from studies where we used the package auk to approximate species' geographic

723 coordinates compared to those studies where authors provided information on latitude and

724 longitude. Bars represent 95\% confidence limits. Dashed line indicates the difference from the

725 overall meta-analytical mean. 
Table 1 Integrated models of survival rates across an assemblage of 679 bird species based on only extrinsic (seasonality and latitude)

727 or intrinsic (body mass, clutch size, and migratory habit) moderators or a combined extrinsic / intrinsic model (Joint model). Latitude

728 was fitted with separate intercepts for the Northern and Southern hemisphere. $\triangle \mathrm{AIC}_{\mathrm{C}}$ columns represent the increase in model AIC $\mathrm{C}$

729 when a moderator is dropped relative to the fully parameterized model. Model coefficients $(\beta)$, 95\% confidence intervals are shown

730 for the full models. The Null model AIC for random effects only (phylogeny, study ID, and species nested within study) is listed for

731 comparison.

\begin{tabular}{|c|c|c|c|c|c|c|c|c|c|c|c|c|c|}
\hline \multirow[b]{2}{*}{ Variable } & \multirow{2}{*}{$\frac{\text { Extrinsic }}{\Delta \mathrm{AIC}_{\mathrm{C}}}$} & \multirow{2}{*}{$\frac{\text { Intrinsic }}{\Delta \mathrm{AIC}_{\mathrm{C}}}$} & \multicolumn{5}{|c|}{ Separate models } & \multicolumn{6}{|c|}{ Joint model } \\
\hline & & & $\beta$ & $\begin{array}{l}95 \% \\
\text { LCL }\end{array}$ & $\begin{array}{l}95 \% \\
\text { UCL }\end{array}$ & $Z$ & $p$ & $\Delta \mathrm{AIC}_{\mathrm{C}}$ & $B$ & $\begin{array}{l}95 \% \\
\text { LCL }\end{array}$ & $\begin{array}{l}95 \% \\
\text { UCL }\end{array}$ & $z$ & $p$ \\
\hline Latitude $_{\text {Northern }}$ & 5.84 & & -0.06 & -0.10 & -0.03 & -3.46 & $* * *$ & -2.16 & -0.04 & -0.07 & -0.01 & -2.28 & $*$ \\
\hline Latitude Southern & & & 0.00 & -0.03 & 0.02 & -0.23 & & & 0.00 & -0.03 & 0.02 & -0.29 & \\
\hline Temp Seasonality $_{\text {}}$ & -2.60 & & -0.01 & -0.03 & 0.01 & -1.09 & & -4.07 & 0.00 & -0.02 & 0.01 & -0.12 & \\
\hline Body mass & & 82.97 & 0.05 & 0.04 & 0.06 & 10.04 & $* * *$ & 89.12 & 0.05 & 0.05 & 0.07 & 10.35 & $* * *$ \\
\hline Clutch size & & 70.99 & -0.12 & -0.14 & -0.09 & -9.29 & $* * *$ & 44.97 & -0.10 & -0.13 & -0.07 & -7.40 & $* * *$ \\
\hline Nonmigrant & & 4.73 & 0.03 & 0.01 & 0.05 & 3.02 & $* *$ & -2.44 & 0.02 & -0.01 & 0.04 & 1.48 & \\
\hline $\mathrm{AIC}_{\mathrm{C}}$ of rand & ffects & node & 518 & & & & & & & & & & \\
\hline
\end{tabular}




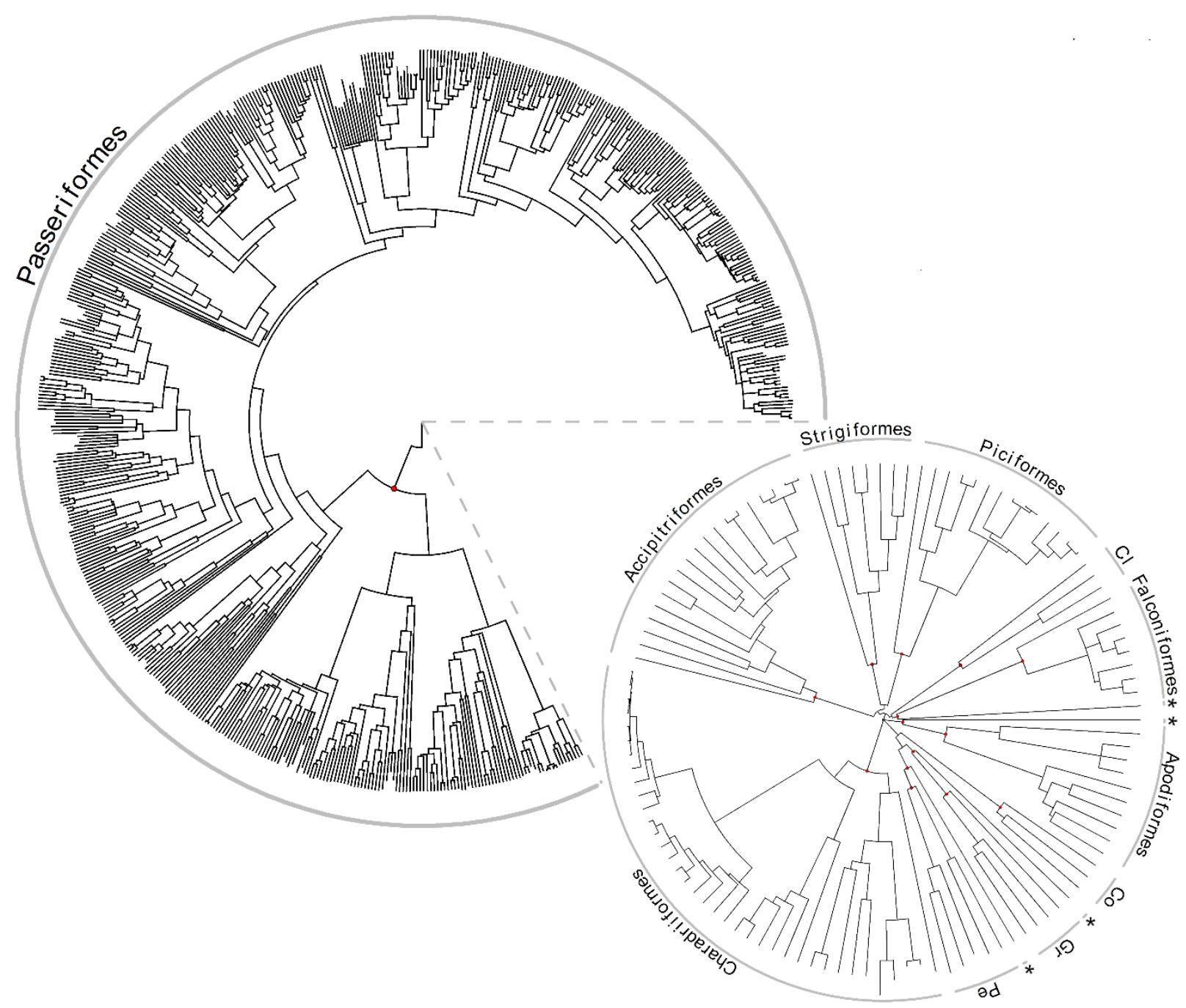

Figure S1 Phylogenetic relationships of the 679 species of birds used in the global meta-analysis of survival rates. Most species $(82 \%)$ were in order Passeriformes. The call out shows nonpasserine orders used in the analysis. Red circles indicate nodes demarking branches for each of the orders. Abbreviations are: $\mathrm{Cl}=$ Coliformes, $\mathrm{Co}=$ Columbiformes, $\mathrm{Gr}=$ Gruiformes, $\mathrm{Pe}=$ Pelcaniformes. From clockwise from top right, asterix symbols show orders represented by a single species: Psittasciformes, Caprimulgiformes, Cuculiformes, Ciconiformes. 


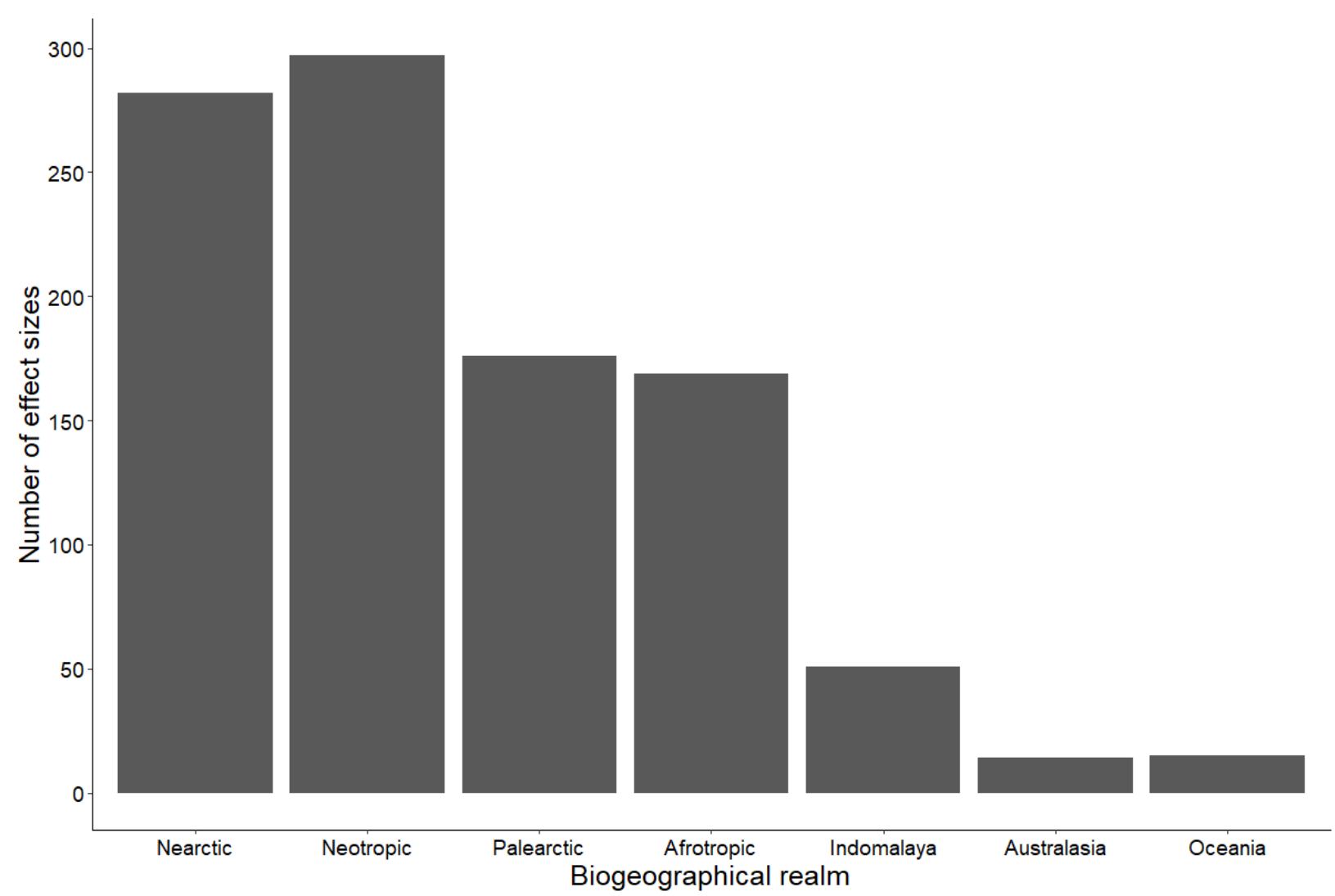

744 Figure S2 Number of effect sizes coming from the biogeographic realms of the world excluding

745 the Antarctic. 


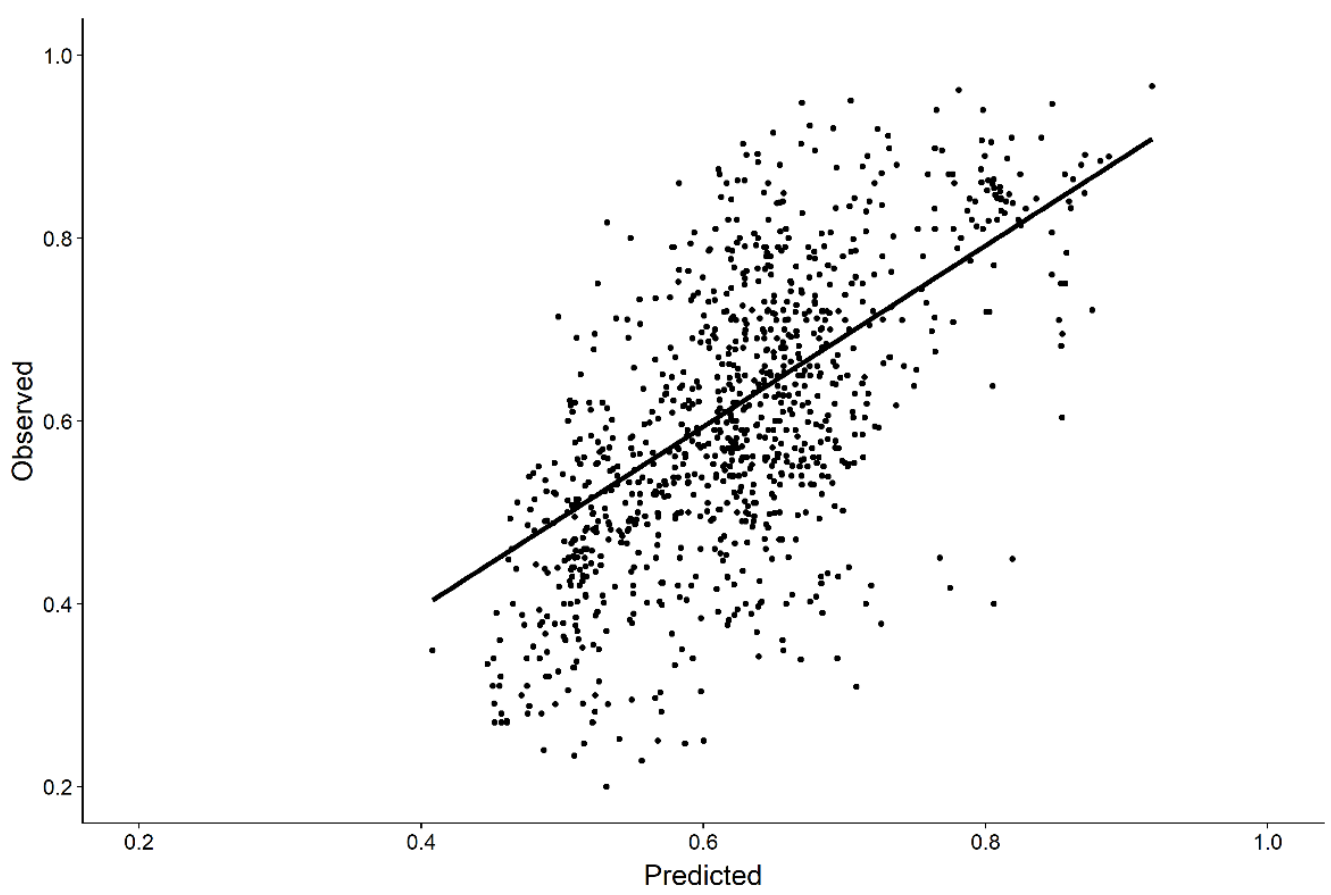

748 Figure S3 Model fit for the observed survival rate and that predicted by the joint extrinsic /

749 intrinsic model (Table 1) for an assemblage of 679 species of birds across the globe.

750

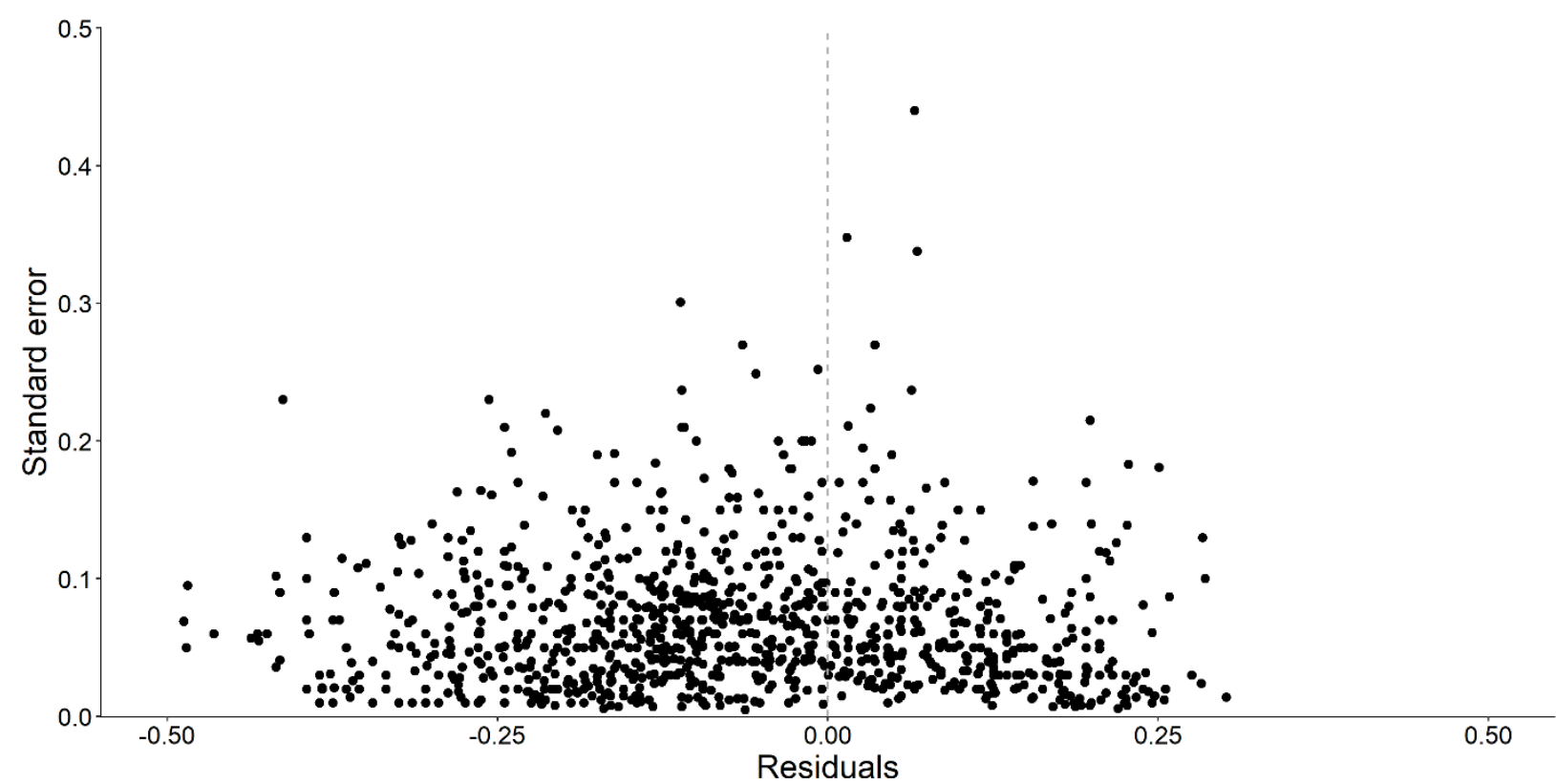

752 Figure S4 Funnel plot used to evaluate publication bias for the global analysis of 1004 effect

753 sizes plotted against their precision. 
754 Table S1 Spearman rank correlations of variables considered for the meta-analysis of avian

755 survival rates. Significant correlations $\geq 0.70$ are highlighted in bold.

\begin{tabular}{lccccccc}
\hline & Latitude & Precip & Temp $p_{\text {Winter }}$ & Temp Seaonality & Clutch & Mass & Nonmigrant \\
\cline { 2 - 7 } Latitude & & -0.28 & -0.63 & 0.64 & 0.10 & 0.57 & -0.67 \\
Precip & -0.28 & & $\mathbf{0 . 7 1}$ & -0.67 & -0.10 & -0.48 & 0.38 \\
Temp Winter $_{\text {Temp }}$ Seaonality & -0.63 & $\mathbf{0 . 7 1}$ & & $\mathbf{- 0 . 9 2}$ & -0.13 & -0.64 & 0.62 \\
Body mass & 0.64 & -0.67 & $\mathbf{- 0 . 9 2}$ & & 0.17 & 0.66 & -0.66 \\
Clutch size & 0.10 & -0.10 & -0.13 & 0.17 & & -0.12 & -0.06 \\
Migratory habit & 0.57 & -0.48 & -0.64 & 0.66 & -0.12 & & -0.50 \\
\hline
\end{tabular}

757 Table S2 Single-predictor meta-regression models of extrinsic and intrinsic moderators

758 hypothesized to effect adult survival rates and ranked by $\mathrm{AIC}_{\mathrm{C}}$.

759

\begin{tabular}{llll}
\hline Model & $K$ & $\mathrm{AIC}_{\mathrm{C}}$ & $\Delta \mathrm{AIC}_{\mathrm{C}}$ \\
\hline Mass & 5 & -1606.11 & 0.00 \\
Clutch & 5 & -1600.92 & 5.19 \\
Latitude & 6 & -1540.16 & 65.96 \\
Seasonality & 5 & -1531.7 & 74.41 \\
Winter & 5 & -1531.18 & 74.94 \\
Migratory & 5 & -1527.77 & 78.34 \\
Precipitation & 5 & -1519.29 & 86.82 \\
Null & 4 & -1516.05 & 90.07 \\
\hline
\end{tabular}

760

761

762

763

764 
766 Table S3 Multi-predictor meta-regression models of either extrinsic climate factors or intrinsic

767 traits. Models were developed by sequentially adding the best performing moderators until AIC

768 was no longer improved, then combining these to form the joint extrinsic / intrinsic model.

\begin{tabular}{|c|c|c|c|}
\hline Model & $K$ & $\mathrm{AIC}_{\mathrm{C}}$ & $\Delta \mathrm{AIC}_{\mathrm{C}}$ \\
\hline Null & 4 & -1516.05 & \\
\hline \multicolumn{4}{|c|}{ Extrinsic climate factors } \\
\hline Temp $p_{\text {Seasonality }}$ & 5 & -1531.70 & 0.00 \\
\hline Temp $p_{\text {Seasonality }}+$ Temp $_{\text {Winter }}$ & 6 & -1528.93 & 2.77 \\
\hline Temp $p_{\text {Seasonality }}+$ Precip & 6 & -1528.64 & 3.06 \\
\hline \multicolumn{4}{|l|}{ Intrinsic traits } \\
\hline Mass + Clutch + Nonmigrant & 7 & -1687.06 & 0.00 \\
\hline Mass + Clutch & 6 & -1682.37 & 4.69 \\
\hline Mass & 5 & -1606.11 & 80.95 \\
\hline
\end{tabular}

770 Table S4 Mean survival rate of each data subset, their upper and lower bound \%95 confidence

771 interval, the number effect sizes in the analysis, and two measure of total heterogeneity:

772 Chochran's $Q$ and $I_{2}$ values.

\begin{tabular}{lllllll}
\hline Data used & $\begin{array}{l}\text { Mean } \\
\text { survival }\end{array}$ & $\begin{array}{l}95 \% \text { CI } \\
\text { lower }\end{array}$ & $\begin{array}{l}\text { 95\% CI } \\
\text { upper }\end{array}$ & $\begin{array}{l}\text { No. effect } \\
\text { sizes used }\end{array}$ & $\begin{array}{l}\text { Cochran's } \\
\text { Q }\end{array}$ & $I^{2}$ \\
\hline All data & 0.66 & 0.48 & .85 & 1004 & $P>0.001$ & 0.99 \\
Nonpasserines & 0.67 & 0.48 & 0.87 & 182 & $P>0.001$ & 0.99 \\
Passerines & 0.64 & 0.41 & 0.86 & 822 & $P>0.001$ & 0.96 \\
Old world & 0.65 & 0.46 & 0.85 & 396 & $P>0.001$ & 0.96 \\
New world & 0.66 & 0.47 & 0.86 & 579 & $P>0.001$ & 0.94 \\
Island & 0.73 & 0.55 & 0.92 & 76 & $P>0.001$ & 0.91 \\
Mainland & 0.65 & 0.47 & 0.83 & 928 & $P>0.001$ & 0.96 \\
\hline
\end{tabular}

